\title{
Numerical simulation on a heavy storm for 26th Jul of Yellow River
}

\author{
LIU Ke ${ }^{1,2}$, LEI Xiaohui ${ }^{1}$, LIU Jifeng ${ }^{2}$, YANG Mingxiang ${ }^{1}$ \\ 1. State Key Laboratory of Simulation and Regulation of Water Cycle in River Basin, China Institute of Water Resources and Hydropower \\ Research, Beijing 100038, China; \\ ${ }^{2}$ Hydrology Bureau of YRCC, Zhengzhou 45004 China )
}

\begin{abstract}
Aiming to investigate the weather characteristics and mesoscale system in the heavy rainstorm process on Jul 26, 2017 of Yellow River, the conventional observations and mesoscale numerical model (WRF) and its assimilation system 3DVAR was utilized to simulate the major precipitation period. The difference between the results of model with assimilation observation date of meteorological observation stations and without assimilation were also discussed. the results indicates that upper at $500 \mathrm{hPa}$ and shear line at $850 \mathrm{hPa}$ form the forward-titling trough which provides favorable instability conditions for generation of rainstorm. stability of subtropical high is beneficial to the water flux transporting to main precipitation zone. the wind shear at $850 \mathrm{hPa}$ and surface cyclone are the mesoscale systems. By comparing the simulations with and without assimilation, the result showed that the simulation with assimilation improved obviously the location of heavy rain and spatial distribution of different levels of precipitation. Of which the region with precipitation below $10 \mathrm{~mm}$ simulated by experiment with assimilation was greatly improved. At the factors of atmospheric circulation field, the intensities of water vapor transportation and surface cyclone have strengthened after assimilation, thus can support more favorable conditions for development of convection's system. its implied that simulations after assimilation improve the spatial structure of initial field, and have an essential effect on simulating mesoscale convective system's structure.
\end{abstract}

\section{Introduction}

Rainstorm over China and its damage were the one of the major natural calamity in China. emphases and difficulties always consist in lie in the heavy rain forecasts and researches for the complexity of rainstorm physics mechanism. there were many intentional researches concerning the heavy rain forecast skill after years of research. but the forecast skills about heavy rainfall area and the predictability time were barely satisfactory. at the same time, observation ability and temporal-spatial resolution of data restricted the weather system identification to a certain degree(Zheng et al. 2009). all the more so when referring to local heavy rain with small spatial scale, short life and complicated. heavy rainfall was the result of interaction among multi-scale weather systems. the large scale circulation provideed advantage condition for moisture transport, and the meso-micro scale weather system made a direct contribution to the heavy rainfall(Jiang et al. 2009). there were some important conditions resulting heavy rainfall, of which triggering mechanism with regional difference played the key role(Tao et al. 1979; Zhang et al., 2012; Shi et al. 2011). many studies about heavy rainfall in Northern China showed that vertical shear, invasion of cold air in mid troposphere, cold front and topography forcing and so on were the most influential factors(Guo et al., 2006; Li et al. 2011).

There was a local heavy rainfall process that happened in Wu ding river of Yellow River Basin in 26Jul 2017, the valleys of middle reaches of the Yellow River including Wu ding river, Wing liangsi river, Qiu shui river and San chuan river were enveloped by heavy rainfall. heavy rainfall center located in $\mathrm{Wu}$ ding river. the day watershed average precipitation of Wu ding river was $67.5 \mathrm{~mm}$. the maximum flood peak of many hydrologic stations in $\mathrm{Wu}$ ding river reached a new high. the maximum flood peak occurred reached to $6010 \mathrm{~m}^{2} / \mathrm{s}$ in Long men station of Yellow River at 01(Beijing) 27jul 2017. this flood process named as NO 1 Yellow River flood of 2017. the strong rainfall period focused on the period from 02(Beijing) to 08 26jul 2017. the spatial domain of strong rainfall acrossed two longitude $\left(109-111^{\circ} \mathrm{E}\right)$, and one latitude $\left(39.5-40.5^{\circ} \mathrm{N}\right)$. and spatial scale belonged to mid$\beta$. now the observation network was hard to find those rain system(Qi and Zhao 2003). high-resolution numerical models was the powerful tool to study mid-scale heavy rain. because of the time and space uneven distribution of observation records, numerical weather prediction errors came from the initial condition. the data assimilation was 
the important way to optimize the model initial condition, and then got better effect of prediction(Zhang et al. 2005). the station routine observation data utilized in data assimilation were same as model input physical variables. so the uncertainty from non-conventional meteorological data was avoided, and the matching performance between model initial condition and data used in model initial data assimilation(Meng et al. 2017).

Therefore, the hindcast experiments using WRFV3.5 was to the analysis the strong heavy rainfall period of NO 1 flood of Yellow River. the experiments included two tests, the one test was with data assimilation, another without assimilation. the evolving and structure of mesoscale weather system was analyzed and discussed.

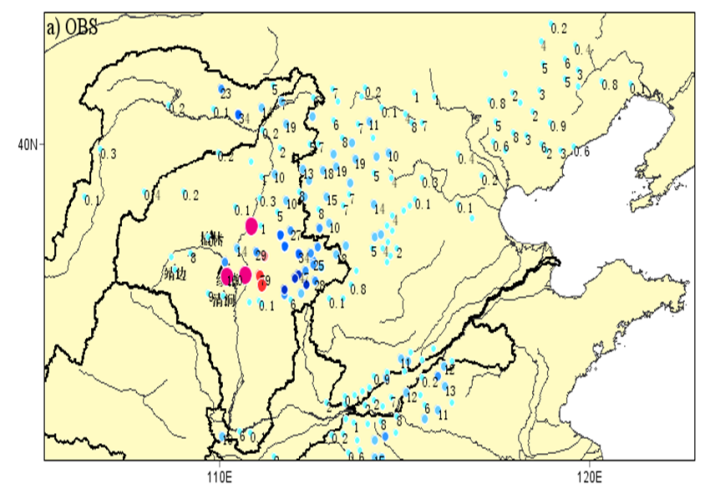

Fig.1 Distribution of $6 \mathrm{~h}$ accumulative precipitation for Shanshan region of the Middle Yellow River(a) and the percentage of 6 level precipitation distribution(b)

12-24 hours before convection unstable energy released, the convection stratification was established(Zhu et al. 2000). at 20(Beijing) 25jul, short wave moved southeast from Central Siberian to $\mathrm{Wu}$ ding valley, and the $\mathrm{Wu}$ ding valley prevailed southwesterly airstream, in higher latitude. in lower latitude, the WPSH steady located in $35^{\circ} \mathrm{N}$, with a clumpy base. southerly wind transported water vapor to middle reaches of Yellow River. at level of $850 \mathrm{hPa}$, a wet and warm shear moved to eastern of middle reaches of Yellow River. convergence was formed by the collision of the southeasterly stream from south of shear and northerly air masses from Hetao area. near surface, the low-pressure center at Si chuan province developed northward to northern Inner Mongolia, and the high-pressure center in Northeastern China southward to North China Plain. Wu ding valley located in front of low-pressure and back of high-pressure. after six hours, the pressure gradient field improved significantly. strong cyclonic shear developed in $\mathrm{Wu}$ ding valley(Figure not shown). In summary, the short heavy rainfall located in front of large-scale west wind. the maintain steady of WPSH, configuration of wind shear and surface convergence line transported water vapor and offered dynamic conditions for the convection.

\section{Satellite TBB data analysis}

Figure 2 showed the TBB evolution processes. it was clearly to see the movement of convective clouds overhead. As time goes by, convective cloud clusters enhanced at 20(Beijing) 25jul 2017, with the strong organized water moisture transport developed(F2a). After six hours, convective cloud clusters centered in east $\mathrm{Yu}$ lin

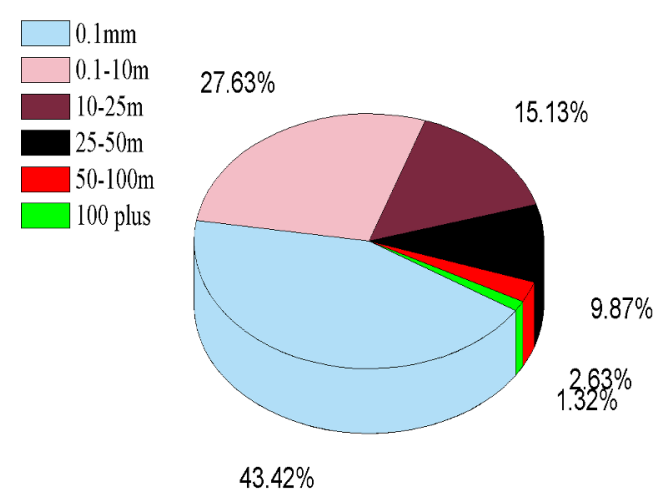

\section{Rainfall field and weather pattern}

Figure 1 showed the spatial distribution of 6-hour (from 02(Beijing) to 08 26jul 2017) rainfall. the area covered with strong rainfall located in $\mathrm{Wu}$ ding valley, and there were three weather station with 6-hour rainfall overlap $100 \mathrm{~mm}$. rainfall of most other weather stations of Yellow River were below $50 \mathrm{~mm}(\mathrm{~F} 1 \mathrm{a})$. the precipitation probability distribution were statistic analyzed(F1b). there were $43.32 \%$ stations with rainfall below $1 \mathrm{~mm}, 27.63 \%$ below $10 \mathrm{~mm}, 15.13 \%$ below $25 \mathrm{~mm}, 16 \%$ below $50 \mathrm{~mm}$ and $1 \%$ above $100 \mathrm{~mm}$. the character of spatial distribution showed the obviously local features.

area (center of heavy rainfall), the TBB lowered to $-40^{\circ} \mathrm{C}$. allowed by main heavy rainfall ended, the edge of convective cloud textured at 04(Beijing) 26jul 2017, and the intensity of convection weaken (F2c). at 06(Beijing) 26jul 2017, convective cloud clusters enhanced again and shifted eastward(F2d).

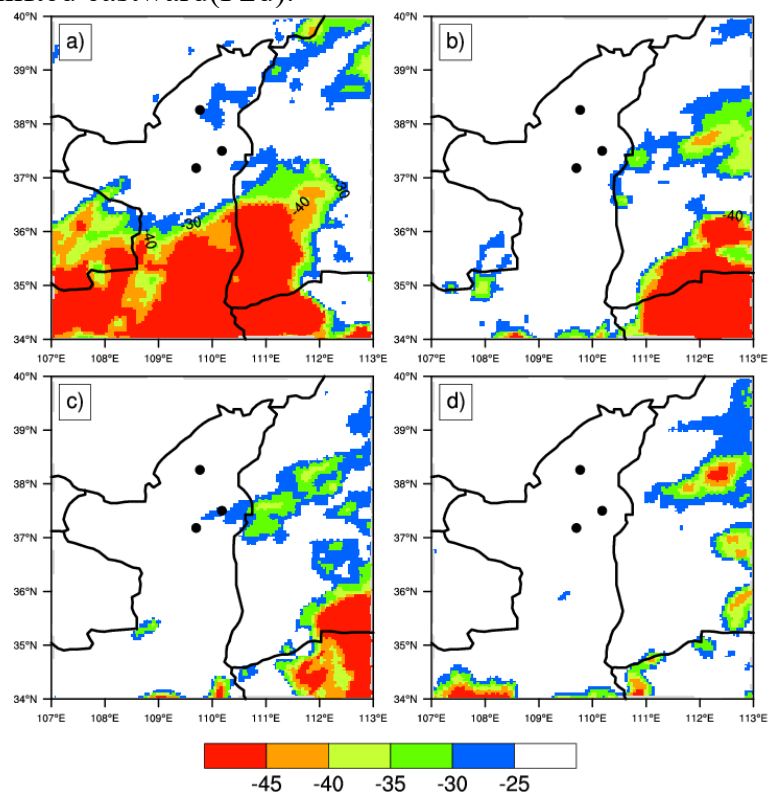

Fig.2 Distribution of TBB $/\left({ }^{\circ} \mathrm{C}\right)$ for satellite FengYun 2e from 12 (a), 18 (b), 20 (c) and 22 UTC (c) 25 July 2017 (black dot donates the center of heavy center )

\section{Result}

The mesoscale numerical model WRFv3.5(Weather Research Forecast) was utilized to predict the processes of 
heavy rainfall. modeling adopted double domain nesting scheme. the center of experiment located in the point of $100^{\circ} \mathrm{E}, 37^{\circ} \mathrm{N}$. the outer and inner layer covered East Asia and Northern of middle stream of Yellow River. the spatial resolution of inner layer was $9 \mathrm{~km}$, and the numbers of modeling grid of outer and inner layers were $193 \times 205$, $103 \times 100$. the initial condition of modeling came from NCEP FNL analysis data(spatial resolution is $\left.1^{\circ} \times 1^{\circ}\right)$. the scheme of microphysical process used WSM6. long wave radiation and short wave radiation scheme adopted RRTM and Dudhia scheme. PBL scheme was YSU scheme. cumulus convective parameterization scheme was GrellDevenyi scheme.

Data used for model initial condition assimilation was from weather station, the physical variables included geopotential height, temperature, dew-point temperature, wind field on pressure levels. the pressure(sea surface pressure), temperature $(2 \mathrm{~m})$, dew-point temperature $(2 \mathrm{~m})$, wind field $(10 \mathrm{~m})$ near surface were also covered. the

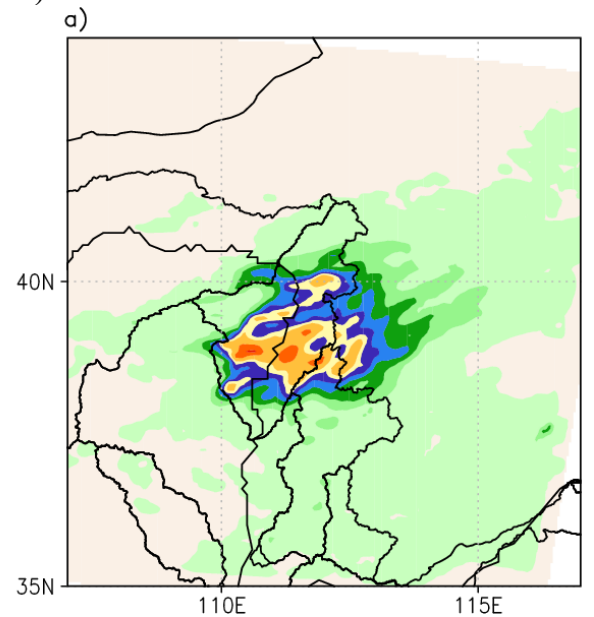

specific technical method about data assimilation was described in detail in WRF technical manual(Skamarock et al. 2008). the modeling period of two experiments included with assimilation and without assimilation covered 20(Beijing) 25jul 2017 to 08(Beijing) 26jul 2017.

Figure 3 showed the spatial distribution of 6 hour precipitation predicted by two modeling experiment. comparing to F1a, the center of heavy rainfall areas by experiment without assimilation was more north than observation, and the domain and intensity of model predicted were bigger and stronger(F3a). F3b expressed the result of experiment with assimilation. comparing to $\mathrm{F} 3 \mathrm{a}$, there were two heavy rainfall centers in an east-west direction, and the domain of heavy rainfall was smaller. the center of heavy rain along the south side was more close to real center of heavy rainfall of observation, but still north to observation. the experiment with assimilation showed the better performance.

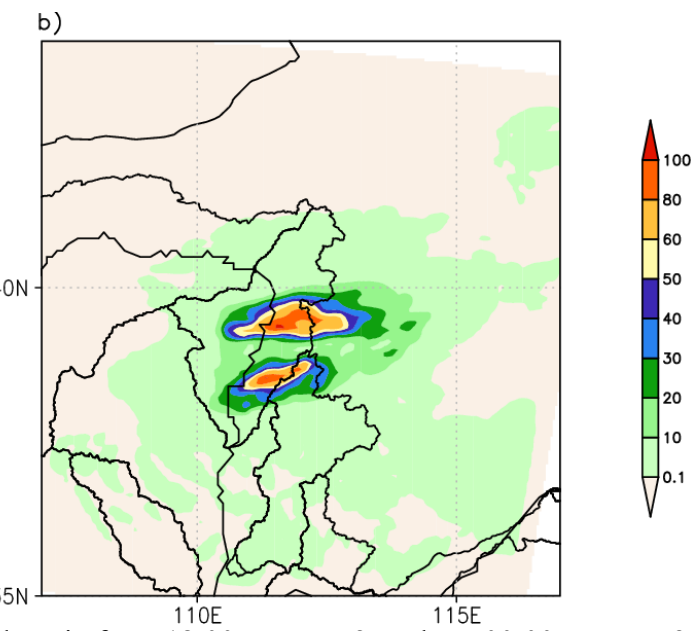

Fig3. Distribution of $6 \mathrm{~h}$ accumulative precipitation for inner domain from 18:00 UTC on 25 July to 00:00 UTC on 26 July 2017 (unit: $\mathrm{mm}$ ). (a) and (b) are distributions of simulated rainfall without and with assimilated sounding data respectively.

The TS(Treat Score) was used to assess the effect of the model simulated with data assimilation(F4). the region valued covered the region from 35 to $45^{\circ} \mathrm{N}$, and from 105 to $115^{\circ} \mathrm{E}$. in summary, the 6-hour precipitation TS of the experiment with data assimilation was $74 \%$, and that without data assimilation was $63 \%$. there were 6 thresholds of precipitation divided by writer to quantitatively evaluated the power of experiment with data assimilation. the precipitation below $10 \mathrm{~mm}$ was improved by data assimilation obviously. but in the thresholds of precipitation from 10 to $50 \mathrm{~mm}$ was barely satisfactory. for the precipitation above $50 \mathrm{~mm}$, the difference between two experiments were small.

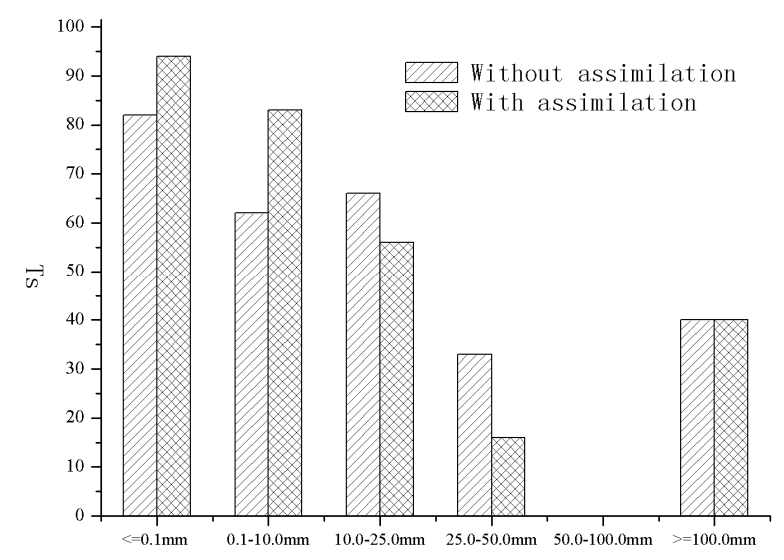

Fig. 4 TS between simulated $6 \mathrm{~h}$ precipitation and observation precipitation in different threshold for $0.1,10.0,25.0,50.0$, $100.0,100.0 \mathrm{~mm}$ plus from 18:00 UTC on 25 July to $00: 00$ UTC on 26 July 2017 (unit: \%)

In order to further study the differences between two experiments, the circulation fields were discussed. F5 showed the anomalies of geopotential height and wind field in 500-hPa at 02(Beijing) 26jul 2017 simulated by two experiments. the spatial of two experiments expressed some difference on location of WPSH. for experiment with data assimilation(F5b), the location of WPSH was eastern and southern than that without assimilation(F5a). 
west wind was similar in two experiments. the intensity of west wind $500-\mathrm{hPa}$ simulated were weak, southwesterly wind speed was $4-6 \mathrm{~m} / \mathrm{s}$, trough-line showed a northeastsouthwest trend. in the region with strong rain $(\mathrm{F} 5 \mathrm{c})$, there
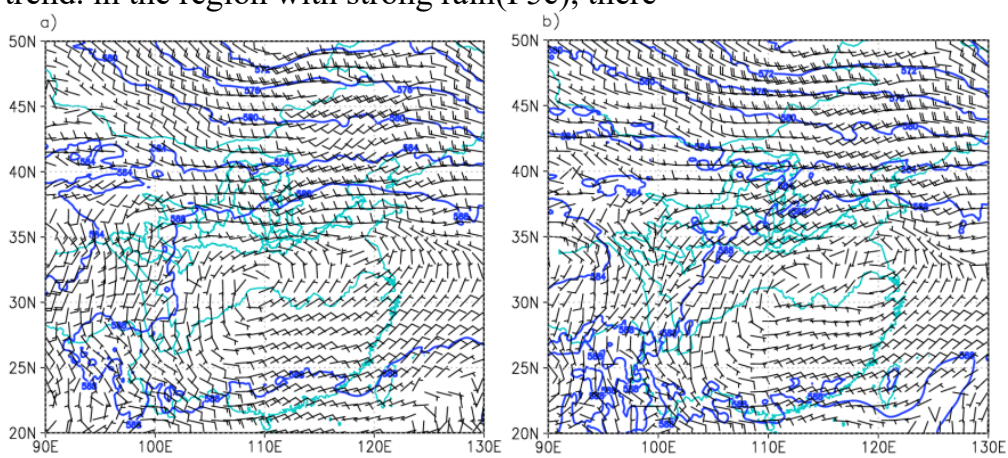

were positive anomalies in geopotential height in $500-\mathrm{hPa}$ simulated by that with assimilation, and the cold air southern to the region near $35^{\circ} \mathrm{N}$.

Fig.5 Composition of 500-hPa geopotential height field (contour, unit: gpm) and initial wind field (barb, unit: $\mathrm{m}^{\cdot} \mathrm{s}^{-1}$ ) for the 18:00 UTC on 25 July 2017. (a) and (b) are distributions of simulated rainfall without and with assimilated sounding data respectively, (c) b minus a.

Abundant water vapor transport was an important condition to formation of heavy precipitation. there were two water vapor sources transporting moisture to the heavy rain. WPSH's southwestern wind and the southerly wind at the side of the shear line supplied plenty of moisture. convergence were induced by southerly wind, the cyclonic circulation was enhanced obviously which located in Hetao area. for the spatial distribution of CAPE(Convective Available Potential Energy), the high CAPE (max close contour line labeled by $60 \mathrm{~J} / \mathrm{Kg}$ )was round the region with heavy rain, but the domain with high values had some local feature. in two experiment, the
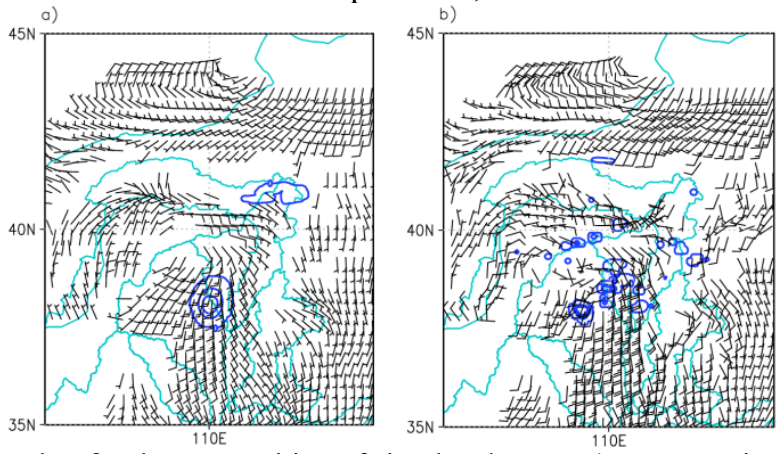

Fig.6 Same as Fig.5. but for the composition of simulated CAPE (contour, unit: $\mathrm{J}^{110 \mathrm{~kg}^{-1}}$ ) and $850 \mathrm{hPa}$ wind field (barb, unit: $\mathrm{m} \cdot \mathrm{s}^{-1}$ )

Triggering mechanism is the main indicator of heavy rainfall. Figure 8 showed the sea level pressure(SLP) and wind field at 10-m. the result of experiment(F7a) without data assimilation expressed that there were perfectly formed structure, the region with heavy rainfall was diminated by prevailing southerly wind. but for the experiment with data assimilation(F7b), the surface cyclonic circulation was loosely structured. there were big pressure gradients in western of North China plain in two experiments. the differences of two experiments were focused on wind field(F7c), the wind convergence center

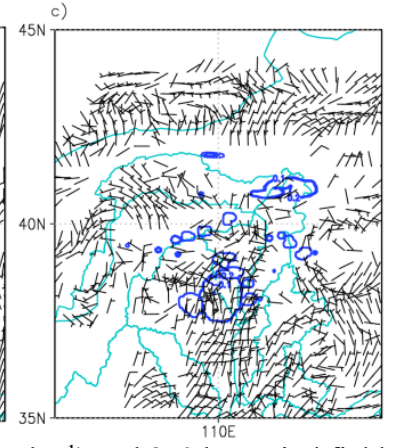

experiment without data assimilation(F6a) showed a organizational cyclonic circulation, and the high value of CAPE was more concentrated than experiment with assimilation(F6b). the differences between two experiments focused on the regional features of CAPE. in the region with heavy rainfall, the CAPE in experiment with data assimilation was more decentralized which make a popcorn shaped. and the southerly wind in 850$\mathrm{hPa}$ was weaker than experiment without assimilation. it means that after data assimilation the mixing of cold and warm was enhanced in local scale.

was located in Northern of Yellow River basin, and the northerly wind anomalies had covered the southern of middle reaches of Yellow River basin. this expressed that the cold air had invaded more southward in experiment with data assimilation than that in experiments without assimilation. the wind convergence center was correspond to the heavy rainfall center simulated in experiment with data assimilation. and the structured cyclonic circulation from experiment without data assimilation had increased the intensity of convection, then lead to a larger scale, stronger intensity. 

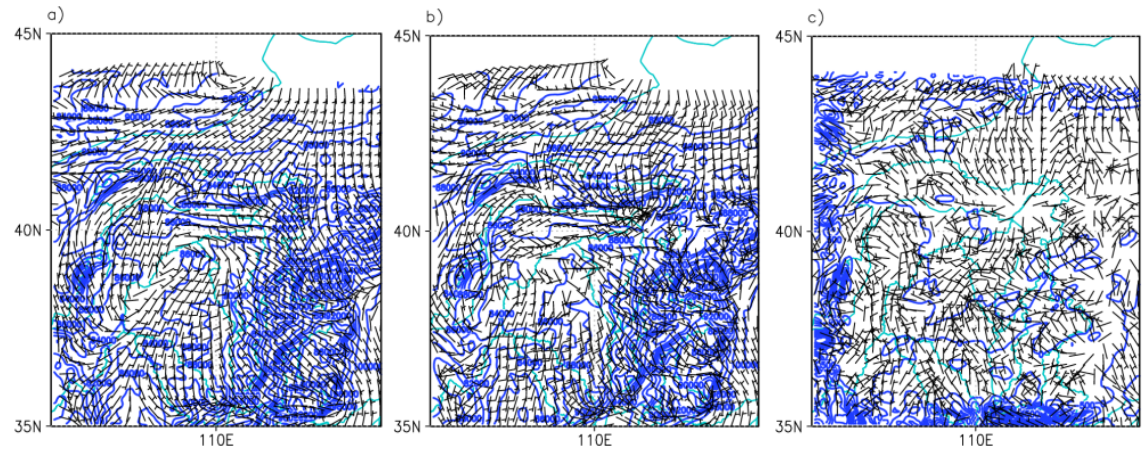

Fig.7 Same as Fig.5. but for the composition of simulated surface
In a view of system configuration, the circulation structure feature of upper lower layer shaped like tilting trough. slot line at $500-\mathrm{hPa}$ surpassed the wind shear of 850-hPa and surface cyclone. the cold air invaded southward in mid troposphere into southern middle reached of Yellow River basin, and overlaid to the wet and warm stream of lower troposphere. the region between troughs and surface cyclone accumulated plenty of instable energy, and the instable energy released in windward slope. the instable energies showed by $\theta_{\text {se }}$ on $850-\mathrm{hPa}$ in Figure 8 . the axis of $\theta_{\text {se }}$ on $850-\mathrm{hPa}$ ran slightly from the northeast to southwest. movement path of convective cloud also exhibited northeast to southwest orientation, and acted in accordance with $\theta_{\text {se }}$ on $850-\mathrm{hPa}$. the heavy rainfall occurred in west of axis of $\theta_{\text {se }}$ on 850$\mathrm{hPa}$.
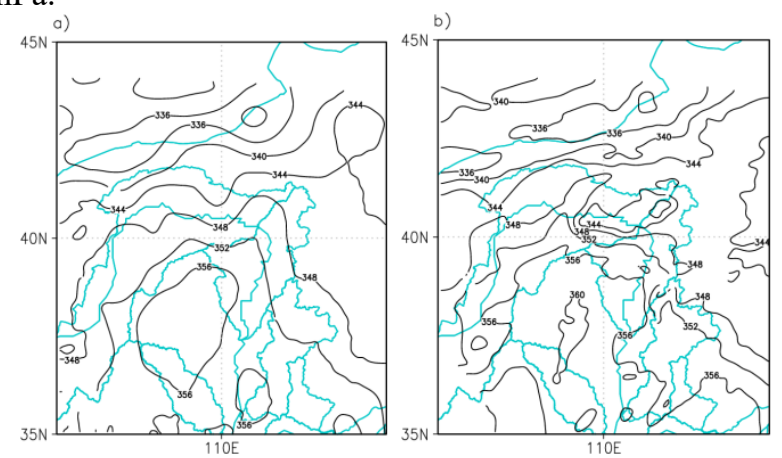

Fig.8 Distribution of $\theta_{\text {se }}$ field on $850 \mathrm{hPa}$ for the 18:00 UTC on 25 July 2017 (contour, unit: K). (a) and (b) are distributions of simulated $\theta_{\text {se }}$ with and without assimilated sounding data respectively.

\section{Conclusion}

The local short heavy rainfall process which occurred in $\mathrm{Wu}$ ding valley of middle reaches of Yellow River possessed the characteristics of tilting trough. west wind, wind shear and surface cyclone were the mesoscale weather system. surface cyclone triggered the convection, and southerly wind in lower troposphere supported plenty of water to heavy rainfall. the wet and warm air accumulated below 500-hPa. near surface, the cold air invaded southward just near surface. the instable energy store in lower troposphere released with short wave on 500-hPa moved eastward also with surface cyclone near surface.

WRF was used to study the evolution of mesoscale weather system. the forecast skill of two experiments was also discussed. the main findings are summarized as follows:

1) The experiment with data assimilation gave the better forecast skill. for the precipitation below $10 \mathrm{~mm}$, the experiment with data assimilation gave superior result. for the precipitation above $10 \mathrm{~mm}$, the experiment with assimilation gave similar result with that without data assimilation. the experiment with data assimilation showed more localized heavy rain, and made the TS lower than that without data assimilation.

2) For the circulation simulated by two experiments, the experiments with data assimilation showed southward movement slightly, and southerly wind weakened in $\mathrm{Wu}$ ding valley of middle reaches of Yellow River basin. near surface, the more southerly cold air invaded simulated by experiment with data assimilation. the differences in factor of circulation configuration between two experiments expressed that weaken convective intensity in experiments with data assimilation. the more weaken convective intensity, the more local heavy rainfall. in a summary, thought the TS for the precipitation above $25 \mathrm{~mm}$ was lower than that without data assimilation, the local feature was simulated by the experiment with data assimilation. and the result was more close to observations.

It was well known that surface observation net work can't monitor meso-micro scale weather system now, corresponding to the nonconventional observational data. in order to avoid to non-authenticity from nonconventional observational data(such as. satellite or radar and so on). the data of surface automatic weather stations should get more attentions in WRF forecast. on the other hand, the physical mechanism of heavy rainfall in middle reaches of Yellow River basin also should be paid close attention, especially for the factor of terrain in heavy rainfall.

\section{Acknowledgment}

The study is financially supported by the National Natural Science Foundation of China (No. 017YFC0404400)

\section{References}

1. Zheng, Z. F., Zhang. X. L.2009: Numerical simulation and analysis on a local heavy rain in Beijing[J]. Journal of Tropical Meteorology, ,25(04):442-448. (in Chinese)

2. Jiang. L. H., Zhang. X. Y., and Zhuang. Z. B.2013: Numbeircal simulation on a heavy rainstorm process in Beijing $[\mathrm{J}]$. Journal of Meteorology and 
Environment. 29(04):18-25. (in Chinese)

3. Tao. S. Y., Ding. Y. H., and Zhou. X. P., 1979: Research of rain storm and strong convection weather[J]. Chinese Journal of Atmospheric Sciences, 3(2):227-238. (in Chinese)

4. Zhang. X. L., Chen. Y., Zhang. T., 2012: Meso-scale convective weather analysis and sever convective weather forecasting $[\mathrm{J}]$. Acta Meteorologica Sinica, 70(04): 642-654. (in Chinese)

5. Shi. Y. R., Shou. Sh. W., and Wang. L. R., et al. 2011: Relationship between storm relative and types of strong convective weather[J]. Journal of Meteorology and Environment, 27(1):65-71. (in Chinese)

6. Guo. H., Ji. CH. P., Zhang. L. N., et al. 2006: A case study of local rainstorm in Beijing on 10 July 2004: the analysis of the gravity wave[J], Chinese Journal of Atmospheric Sciences, 30(04):703-711. (in Chinese)

7. Li. CH. M., Miao. SH. G., Zhang. Z. F., et al. 2011: Formation and effect of surface convergence line in local rainstorm process of Beijing $[\mathrm{J}]$. Plateau Meteorology, 30(05):1232-1242. (in Chinese)

8. Qi. L. L., Zhao. S. W., 2003: A numberical simulation of the heavy rainfall in Shanghai using nonconventional observational data[J]. Climatic and Environmental Research, 8(04):417-435. (in Chinese)

9. Zhang. A. Zh., Qin. L. L., Ji. F., et al. 2005: Advancement in data assimilation method research[J]. Meteorological Science and Technology, 33(05):385389+393. (in Chinese)

10. Meng. X. W., Long. X., Zhou. G. B., et al. 2017: Numbercial simulation anslysis on conventional data assimilation for a rainstorm in Chongqing[J]. Torrential Rain and Disasters,36(04):309-318. (in Chinese)

11. Zhu. Q. G., Lin. J. R., SHou. S. W., et al. 2000: The principles and methods of synoptic meteorology[M]. Beijing: China Meteorological Press, 430-432. (in Chinese)

12. Skamarock W C, Klemp J B, Duhdia J,et al. A Description of the Advanced Research WRF Version $3[\mathrm{R}]$. National Center for Atomospheric Research (NCAR) technical note VCAR/TN-475+STR, 2008. 